\title{
The UK's dysfunctional relationship with medical migrants: the Daniel Ubani case and reform of out-of-hours services
}

\author{
Julian M Simpson and Aneez Esmail
}

\begin{abstract}
In 2008, a patient died in the UK after being given an excessive dose of diamorphine by an overseastrained doctor working in out-of-hours $(\mathrm{OOH})$ primary care. This incident led to a debate on the recourse to international medical graduates and on the shortcomings of the $\mathrm{OOH}$ system. It is argued here that a historical reflection on the ways in which the NHS uses migrant labour can serve to reframe these discussions. The British Medical Association, the General Medical Council, and the House of Commons Health Committee have emphasised the need for more regulation of overseas graduates. Such arguments fit into a well-established pattern of dependency on and denigration of overseas graduates. They give insufficient weight to the multiple systemic failings identified in reports on $\mathrm{OOH}$ provision by the Department of Health and the Care Quality Commission. Medical migrants are often found in under-resourced and unpopular parts of healthcare systems, in the UK and elsewhere. Their presence provides an additional dimension to Julian Tudor Hart's inverse care law: the resources are fewer where the need is greatest, and the practitioner dealing with the consequences is more likely to be a migrant. The failings of the UK $\mathrm{OOH}$ system need to be understood in this context. Efforts to improve $\mathrm{OOH}$ care should be focused on controlling quality rather than the movement of doctors. A wider reflection on the nature of the roles that international medical graduates are asked to play in healthcare systems is also required.
\end{abstract}

\section{Keywords}

medical history 20th cent; medical history 21st cent; medical staff; migrants; out-of-hours medical care; primary health care.

\section{INTRODUCTION}

In February 2008, a British patient, David Gray, died after he was accidentally administered a lethal dose of diamorphine by Daniel Ubani, a Nigerian-born doctor based in Germany. Ubani was employed by an agency and worked shifts as a GP providing out-of-hours $(\mathrm{OOH})$ care in the UK. The incident has led to an ongoing debate in the UK about how such services are delivered and how they can be improved. A number of reports have now been published, and a range of recommendations and suggestions have been made. ${ }^{1-4}$ So far, the arguments have focused on the competence of European doctors working in the UK $\mathrm{NHS}$ and on failures within the healthcare system. What has not been addressed is the question of the type of roles that migrants are expected to take on and the kind of pressures they are exposed to, as a result, in the NHS. The UK has historically been dependent on medical migration but there has been little acknowledgement of the extent of this dependency and how it might affect the way in which health care is delivered. ${ }^{5}$ Historicising policy questions has the potential to reveal new dimensions to them. ${ }^{6}$ In the absence of such an approach, $\mathrm{OOH}$ care in the UK may well improve if recommendations regarding its systemic failings are followed. An awareness of the historical background to such cases would, however,

JM Simpson, MA, DipIEP, DipESJ, PhD researcher; A Esmail, $P h D, M F P H M, M R C G P, F R C P$, professor of general practice, The University of Manchester, Manchester.

Address for correspondence

Mr JM Simpson The University of Manchester, School of Community-based Medicine, Floor 5, Williamson Building, Manchester, M13 9PL.

E-mail: julian.simpson@postgrad.manchester.ac.uk

Submitted: 15 October 2010; Editor's response: 18 October 2010; final acceptance: 19 October 2010.

(c)British Journal of General Practice 2011; 61: 208-211.

DOI: 10.3399/bjgp11X561230 
help maintain a focus on systems that would seem more conducive to the improvement of health care than ongoing criticisms of foreign doctors. It would also bring to the fore other areas of care that are likely to remain affected by the sort of structural issues that contributed to the unnecessary death of a patient. Reinterpreting some of these questions is important in a British context. It is also of wider relevance in light of the international movement of doctors and the dependency of a number of countries on international medical graduates.

\section{THE DANGERS OF OVEREMPHASISING INDIVIDUAL RESPONSIBILITY OVER SYSTEMIC FAILURE}

In reflecting on what lessons should be learned from the Ubani case, the British medical and political establishments have placed a great deal of emphasis on questioning the abilities of non-UK doctors who come to work in the UK. The chairman of the British Medical Association Council, Hamish Meldrum, said that:

'It cannot be acceptable for poorly trained, badly regulated doctors whose knowledge of English is about as good as my knowledge of Chinese, to be able to practise, virtually unchallenged, in the UK."

A similar line is taken by the General Medical Council which is arguing for a change to regulations, which would enable it to test the language and clinical skills of doctors from European Union (EU) countries. The House of Commons Health Committee stated in March that:

'... the use of EEA [European Economic Area] doctors and the failure to check their language skills and clinical competence ... led to the killing of a patient, Mr Gray, by Dr Ubani, a German locum. ${ }^{2}$

Such views of the root causes of the death of $\mathrm{Mr}$ Gray are somewhat restrictive. Clearly nobody would argue that the NHS should not recruit doctors with good medical skills and good English. It is, however, possible for those employing GPs to test the language skills of doctors, and indeed primary care trusts (PCTs) have a legal duty to verify that the clinicians working in the areas they have responsibility for are fit to provide care for patients, as the then Minister of State for Health, Mike O'Brien, stated unambiguously in front of the House of Commons Health Committee. ${ }^{2}$

The reports produced by the Department of Health $^{1}$ and the Care Quality Commission ${ }^{3}$

\section{How this fits in}

The death of David Gray in 2008 following a mistake by an overseas doctor providing out-of-hours care has led to calls for greater regulation of medical

migrants. This paper argues that an appreciation of the historical dependency of

the NHS on migrants to provide services in under-resourced and unpopular

areas can provide a different perspective on the issues involved. It concludes

that concentrating on systemic reform would be more productive than

introducing new regulations for international medical graduates, and that a wider discussion of how healthcare systems use medical migrants would be beneficial.

(England's healthcare regulator) provide a wealth of evidence that adequate management systems and the implementation of existing guidance would have gone a considerable way towards making the events of 2008 unimaginable. The former makes it clear that the Department of Health has the necessary authority to provide guidance to PCTs when it comes to decisions regarding their ability to evaluate the knowledge of English of doctors wishing to be admitted to medical performers' lists and to invite applicants to discuss their applications. It also makes a number of recommendations regarding performance management and training. The Care Quality Commission points to the failure of Take Care Now (TCN), the company employing $\mathrm{Dr}$ Ubani, to learn the lessons from two previous overdoses of diamorphine, both involving doctors trained in Germany who came to the UK to work shifts for TCN. Nor did TCN review its use of diamorphine following an alert on this subject from the National Patient Safety Agency, which issued a safer practice notice in 2006 because of reports of deaths due to the administration of high doses of diamorphine or morphine. The Care Quality Commission also notes that $\mathrm{Dr}$ Ubani was unsuccessful in his attempt to join the Leeds PCT performers' list because of concerns over his language skills and references.

The issue of controlling access to the UK medical market by overseas doctors would become secondary in an environment where safety alerts are taken seriously and quality is properly monitored. Cosford and Thomas are therefore right to call for the medical profession to take the lead in promoting quality and safety in $\mathrm{OOH}$ care. ${ }^{4}$ The real challenge is to understand why parts of the NHS are employing doctors with questionable skills (irrespective of their nationality) and presiding over systems that put patients at risk. Addressing these systemic problems should be a priority, particularly as concentrating on issues around foreign graduates ignores the fact that in their absence a problem could occur as a result of a British doctor making a mistake, or because no doctor was there at all. 


\section{INTERNATIONAL MEDICAL GRADUATES, DEPENDENCY, AND DENIGRATION}

It is important to reflect on the way in which the UK has dealt with the $\mathrm{OOH}$ controversy, because the UK pattern of simultaneous dependency on and denigration of overseas doctors is not new. ${ }^{8}$ Migrant doctors have traditionally worked in areas that were unpopular with British graduates: primary care in inner-city areas, (ex-)mining communities, and areas with high migrant populations; provision of care for people with mental health difficulties; and care for the elderly. ${ }^{5}$ This has historically involved engaging with indigenous populations marginalised by medical practice. ${ }^{5}$ Migrant doctors have also been an important resource for the NHS when it comes to providing services to other migrants who may be faced with barriers in accessing healthcare as a result of discrimination or cultural and/or linguistic obstacles. ${ }^{9,10}$ Migrant practitioners have been part of debates around these issues for decades ${ }^{11}$ and contribute to improving the quality of care delivered in the UK; for instance by providing consultations in languages other than English. ${ }^{12}$

Similar patterns of recourse to international medical graduates to fill posts deemed unattractive by local graduates can be found elsewhere. Aboriginal Health Services in Australia are reliant on overseas doctors, ${ }^{13}$ and in their study of the immigration of physicians to Canada between 1954 and 1976, Mullally and Wright found that less affluent provinces such as Newfoundland and Saskatchewan were the earliest and most active recruiters of migrant doctors. ${ }^{14}$ Over one-third of doctors working in the UK and New Zealand, around one-quarter of those working in the US, and onefifth of those employed in Sweden have trained abroad. ${ }^{15}$ This dependency has historically coexisted with discrimination, ${ }^{16}$ and with a tendency to consider medical migrants to be less qualified than local graduates, in particular if they come from non-Western countries. ${ }^{17}$ Prejudice blighted the careers of the hundreds of Jewish doctors who came to the UK during and before World War II. ${ }^{18}$ The current discourses around EU doctors in the UK are reminiscent of criticisms made of doctors from the Indian subcontinent in the 1970s. In 1975, one of the first generation of South Asian doctors to work in the NHS, Krishna Korlipara noted that:

'Over the past few months articles in both the lay and medical press have expressed concern at the allegedly low standards of medical care provided by overseas doctors in this country and have particularly criticised the difficulties overseas graduates are alleged to experience in understanding and speaking English. ${ }^{119}$
He went on to point out how dependent British medicine had become on migrants, and stated that:

'To benefit from their presence and at the same time accuse them of being dangerous to the community is like inviting a man for a meal and stabbing him at the table."19

\section{MEDICAL MIGRANTS AND THE INVERSE CARE LAW}

The fact that these overseas doctors take on unpopular roles in the NHS in effect adds an additional dimension to the inverse care law. ${ }^{20}$ Julian Tudor Hart's thesis was that resources tended to be fewer where the need was the greatest. One can add to this that the concentration of migrant professionals will most likely be higher. The UK's reliance on migrants is also an unspoken element of Webster's argument regarding the historical underfunding of the NHS. ${ }^{21,22}$ Their presence allowed services to expand while expenditure was kept under control. $\mathrm{OOH}$ care, in the way in which it has developed in recent years in the UK, can be seen as part of this trend. It involves providing care for people with urgent, often more complex needs, during unsociable hours. Compared to what doctors can earn elsewhere, the financial rewards are limited: TCN, which employed Dr Ubani, paid rates starting at $£ 45$ an hour.

Increased regulation will not solve the ongoing problem of low-priority, insufficiently-resourced, high-need areas, where migrants are employed in large numbers. Moves to improve $\mathrm{OOH}$ care will not make this problem go away either. Increased investment and improved conditions might well improve some care outcomes, but as long as certain parts of the NHS remain under-resourced and undervalued, there is a risk that a similar problem will emerge in another part of the system. Policy makers and the medical establishment need to reflect on the flight from care for the vulnerable and the marginalised, jobs that are undervalued and under funded, and unsociable hours. There are in effect two possible strategies here. Either the UK decides to invest in training increased numbers of doctors and paying them more to work in hitherto unpopular areas so that it can become self-sufficient in medical labour, or it accepts that the financial burden that would create is such that it cannot be taken on by the British state. The ability of the present government to deliver self-sufficiency has to be questionable given the line it has taken on public expenditure. If the path of continuing dependency on migrants is chosen, support for foreign graduates needs to become an essential part of healthcare provision. The approach that has been followed 
since the inception of the NHS - employing overseas doctors, placing them in areas where the need is greatest, where resources are scarce, providing them with inadequate support, and holding them responsible when things go wrong - has to be unsatisfactory.

\section{WIDENING THE DEBATE}

Unless UK doctors decide en masse that they have a social duty to treat marginalised populations and work unsociable hours, or the government makes it much more financially attractive for them to do so, migrants doctors are likely to continue to play a key role in the NHS. Reforming $\mathrm{OOH}$ provision should form part of a wider discussion that would examine how the UK uses medical migrants and the priority it gives to the type of health care they deliver (that is, to older people, ethnic minorities, people living in deprived areas, or those requiring around-the-clock care). The NHS has so far had a dysfunctional relationship with overseas personnel, who are essential to its functioning but regularly constructed as a problem to be dealt with rather than part of the solution.

A programme of reflection is needed on how to emerge from this vicious circle. Listening to the views of migrant doctors on what is wrong with the $\mathrm{NHS}$ and the way health care is run in the UK would be an interesting starting point. Giving a voice to these marginalised practitioners would help bring into focus the needs of the marginalised populations that they serve. Older patients, people with mental health problems, migrants and ethnic minorities should clearly also be part of this conversation exploring why their needs are not prioritised by governments and the medical profession. This would involve taking an ethical approach to medical provision rather than one driven by political or media agendas. Given the similar patterns observed elsewhere in the deployment of overseas staff, it is unlikely that this is a debate that needs only to take place in the UK.

\section{Funding body}

The University of Manchester and The Medical Research Council (Doctoral Training Grant).

\section{Competing interests}

The authors have stated that there are none.

\section{Discuss this article}

Contribute and read comments about this article on the Discussion Forum: http://www.rcgp.org.uk/bjgp-discuss

\section{REFERENCES}

1. Colin-Thomé D, Field, S. General practice out-of-hours services: Project to consider and assess current arrangements. London: Department of Health, 2010.

2. House of Commons Health Committee. The use of overseas doctors in providing out-of-hours services. Fifth report of session 2009-10. Report, together with formal minutes, oral and written evidence. London: The Stationery Office, 2010.

http://www.publications.parliament.uk/pa/cm200910/cmselect/cmheal th/441/441.pdf (accessed 4 Feb 2011).

3. Care Quality Commission. Investigation into the out-of-hours services provided by Take Care Now. London: Care Quality Commission, 2010. http://www.cqc.org.uk/newsandevents/newsstories.cfm?FaAreal=custo mwidgets.content_view_18cit_id=36433 (accessed 24 Jan 2011).

4. Cosford PA, Thomas JM. Safer out of hours primary care. BMJ 2010, 340:c3194.

5. Simpson JM, Esmail A, Kalra VS, Snow SJ. Writing migrants back into NHS history: addressing a 'collective amnesia' and its policy implications. J R Soc Med 2010; 103(10): 392-396.

6 Berridge V. Thinking in time: does health policy need history as evidence? The Lancet 2010, 375 (9717): 798 -799.

7. Boseley S. 'Overseas doctors must speak good English'. The Guardian 2010, 28 June:

http://www.guardian.co.uk/society/2010/jun/28/overseas-doctorsmust-know-english?INTCMP=SRCH (accessed 4 Feb 2011).

8. Kyriakides C, Virdee S. Migrant labour, racism and the British National Health Service. Ethn Health 2003, 8(4):283-305.

9. Kyle D. Better Partnerships, better services. In: Ali S, Atkin K, eds. Primary healthcare and South Asian populations: meeting the challenges. Abingdon: Radcliffe Medical Press, 2004: 51-56.

10. O'Donnell CA, Higgins M, Chauhan R, Mullen K. Asylum seeker's expectations of and trust in general practice: a qualitative study. $\mathrm{Br} J$ Gen Pract 2008; 58(557): el-11.

11. Sayeed A. In the shadow of my Taqdir. Durham: The Memoir Club, 2006.

12. Freeman GK, Rai H, Walker JJ, et al. Non-English speakers consulting with the GP in their own language: a cross-sectional survey. Br J Gen Pract 2002 Jan; 52(474): 36-38.

13. Gilles MT, Wakerman J, Durey A. If it wasn't for OTDs, there would be no AMS': overseas-trained doctors working in rural and remote Aboriginal health settings. Aust Health Rev 2008; 32(4): 655-663.

14. Mullally S, Wright D. La grande séduction? The immigration of foreign-trained physicians to Canada, c.1954-76. J Can Stud 2007; 41(3): 67-89.

15. Buchan J. Challenges for WHO code on international recruitment. BMJ 2010; 340: cl486.

16. Esmail A, Everington S. Racial discrimination against doctors from ethnic minorities. BMJ 1993; 306(6881): 691-692.

17. Wright D, Elis N, Gupta M. The 'Brain Drain' of physicians: historical antecedents to an ethical debate, c1960-79. Philos Ethics Human Med 2008; 3: 24 .

18. Weindling, P. The contribution of Central European Jews to Medical Science and Practice in Britain, the 1930s-1950s. In: Mosse WE, ed. Second chance: two centuries of German-speaking Jews in the United Kingdom. Tübingen: J.C.B Mohr (Paul Siebeck), 1991: 243-254.

19. Korlipara K. The role of overseas doctors in Britain. World Med 1975; 10(18): 44-47.

20. Hart JT. The inverse care law. Lancet 1971; 297(7696): 405-412.

21. Webster C. The health services since the War. Volume I. Problems of health care. The National Health Service before 1957. London: HMSO, 1988.

22. Webster C. The health services since the War. Volume II. Government and health care: the British National Health Service 1958-1979. London: HMSO, 1996. 